\title{
Lithological mapping using Landsat 8 Oli multispectral data in Boumalne, Imider, and Sidi Ali Oubork, High Central Atlas, Morocco
}

\author{
Farah Abdelouhed ${ }^{1,{ }^{*}}$, Ahmed Algouti ${ }^{1}$, Abdellah Algouti ${ }^{1}$. Mohamed Ait Mlouk ${ }^{1}$, and Mohammed ifkirne ${ }^{1}$ \\ ${ }^{1}$ Cadi Ayyad University, Faculty of Sciences, Department of Geology, Geosciences, Geotourism, Natural Hazards and Remote \\ Sensing Laboratory. Bd. BO 2390, 40000 Marrakech,
}

\begin{abstract}
The recognition of geological formations, from a lithological point of view, as well as their tectonic character always remain a major challenge for any precise geological study, in this work we will see the great importance of the application of remote sensing (Landsat OLI, DEM) to realize lithological maps of great interest as well as the realization of detailed lineament maps with the statistics of the performed measurements, the application of some indicated techniques showed a good discrimination of the lithology of geological formations (Fig.8 ,Fig.10,Fig.11),better results and interpretations are also obtained for lineaments affecting the whole area by using the CP1 and DEM methods (Fig.5,Fig.6).Topographic map and geological maps of JBEL SAGHRO DADES and TODGHA MADER (1/200000) gained from ministry of energy and mines, direction of geology (1975), are used for validation of the obtained results by eliminating of artificial structures (roads) and geological layer boundaries. All data sets were pre-processed and projected in the Universal Transverse Mercator (UTM Zone 29 North) projection system and the WGS84 datum using GIS tools (ArcGIS 10.2).
\end{abstract}

\section{Introduction}

The High Atlas of Morocco, representing the southernmost element of the Perimediterrane-an Alpine belt, is a typical example of intracontinental belt [1]. It was formed within the North African plate during convergence of the African and European plates during the Cenozoic $[\mathbf{2 , 3}$. Like other intracontinental mountain belts, the High Atlas shows a double sense of vergence and a complex evolution of timing and sequence of thrusting. The object of this research is on the one hand to test the contribution of the spectral richness of the Landsat 8 OLI sensor in litho-structural mapping in the Eastern Anti Atlas and on the other hand to compare the methods of supervised classification (Spectral Angle Mapper, maximum likelihood), Principal Component Analysis (PCA) and band rations, while evaluating the potential of these three approaches for geological mapping,

\section{Methodology}

The methodological approach followed in this research is illustrated in (Fig.1).

The High Atlas is the masterpiece of the Atlasic domain [4], it is a mountainous barrier much longer than it is wide: $800 \mathrm{Km}$ long and 40 to $80 \mathrm{Km}$ wide. It is elongated in an ENE-WSW direction and forms a typical example of an intracontinental chain located within the
African plate [5]. It is subdivided into three main parts. The Western High Atlas, the Central High Atlas: constitute the median part of this chain between Tizi n'Tichka and the valley of the wadi Ziz, is occupied almost by the folded Mesozoic series and the Eastern High Atlas.

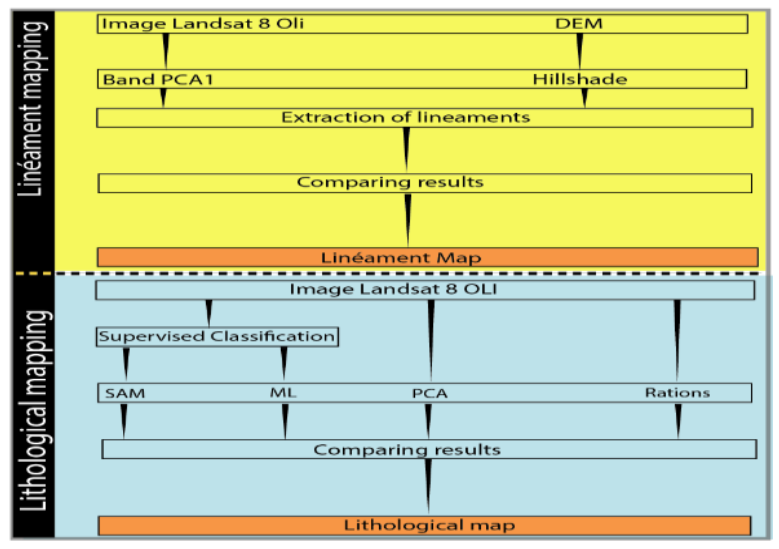

Fig.1. methodology of the main processing steps that performed in the present study.

\section{Study area}

The study site is located in the central border of the Central High Atlas, Morocco. (Fig.2). 


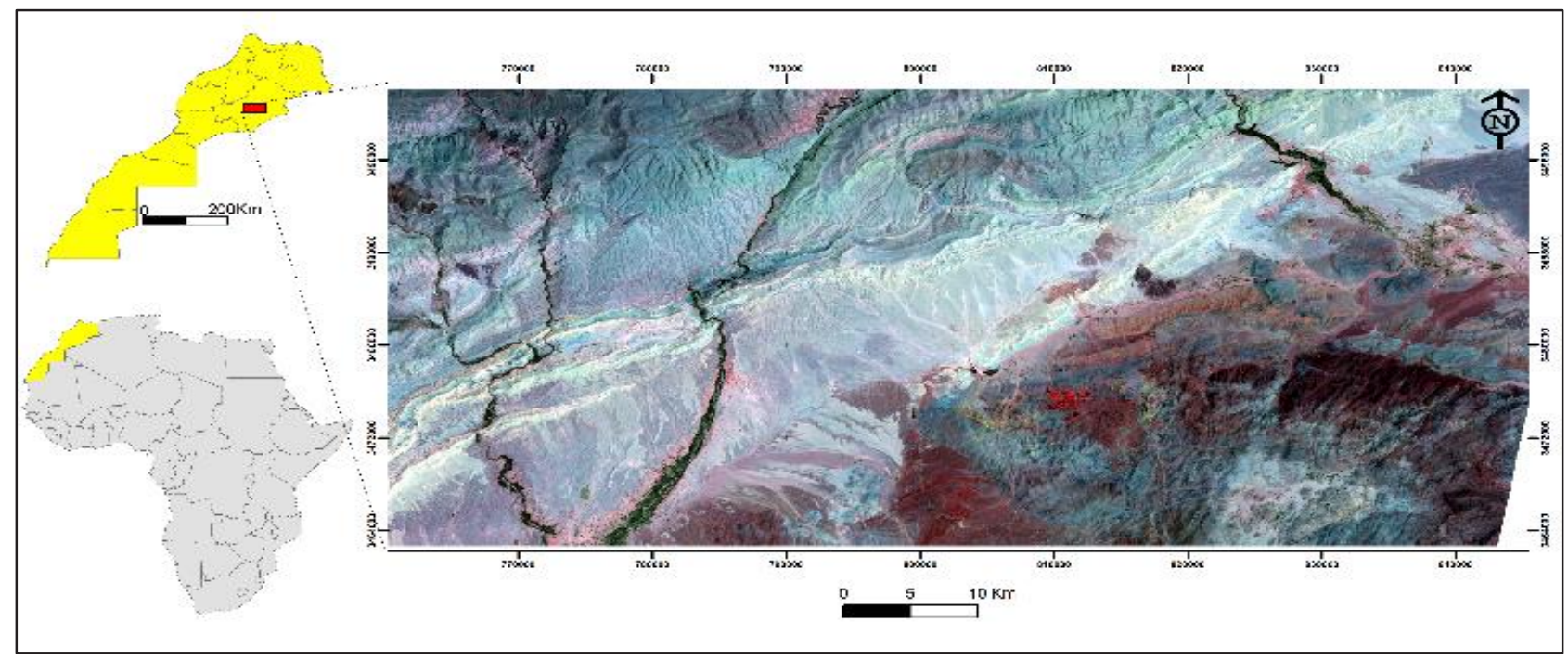

Fig.2. Location of study area.

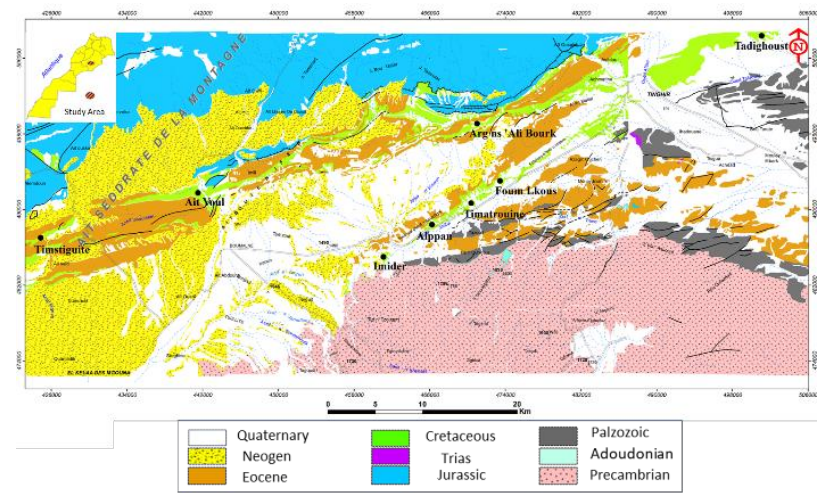

Fig.3. Simplified geological map of the study area (geological map Jbel Saghrou Dades 1 /200 000.modified).

\section{Data used}

The satellite image used in this research was acquired on July 31, 2019 by the Landsat 8 OLI sensor which has the characteristics shown in the figure below [6] STRAUB, Jeremy. Attitudes towards autonomous data collection and analysis in the planetary science community. Galaxies, 2013, vol. 1, no. 1, pp. 44-64.

Digital Terrain Model (STRM) with a resolution of 30 m (USGS, 2019) is used to study the topography of the study area (slope, slopes, shading), as well as the extraction of lineaments.

Topographic map and geological maps of JBEL SAGHRO DADES and TODGHA MADER (1/200000) gained from ministry of energy and mines, direction of geology (1975), are used for validation of the obtained results by eliminating of artificial structures (roads) and geological layer boundaries. All data sets were preprocessed and projected in the Universal Transverse Mercator (UTM Zone 29 North) projection system and the WGS84 datum using GIS tools (ArcGIS 10.2).

The image used in this work is a Landsat 8 OLI image resulting from radiometric calibration (Fig.4), atmospheric corrections and geometric corrections of the raw image (A. Farah et al. 2020).

\begin{tabular}{|llll|}
\hline \hline $\begin{array}{l}\text { Band } \\
\text { Number }\end{array}$ & Spectral Range $(\boldsymbol{\mu m})$ & Instrument & Resolution \\
\hline 1 & $0.43-0.45$ (coastal blue) & OLI & $30 \mathrm{~m}$ \\
2 & $0.45-0.51$ (blue) & OLI & $30 \mathrm{~m}$ \\
3 & $0.53-0.59$ (green) & OLI & $30 \mathrm{~m}$ \\
4 & $0.64-0.67$ (red) & OLI & $30 \mathrm{~m}$ \\
5 & $0.85-0.88$ (NIR) & OLI & $30 \mathrm{~m}$ \\
6 & $1.57-1.65$ (SWIR-1) & OLI & $30 \mathrm{~m}$ \\
7 & $2.11-2.29$ (SWIR-2) & OLI & $30 \mathrm{~m}$ \\
8 & $0.50-0.68$ (panchromatic) & OLI & $15 \mathrm{~m}$ \\
9 & $1.36-1.38$ (cirrus) & OLI & $30 \mathrm{~m}$ \\
10 & $10.60-11.19$ (TIR-1) & TIRS & $100 \mathrm{~m}$ \\
11 & $11.50-12.51$ (TIR-2) & TIRS & $100 \mathrm{~m}$ \\
\hline \hline
\end{tabular}

Fig.4. Landsat 8 OLI and TIRS spectral bands.

\section{Results and Discussion}

\subsection{Extraction of lineaments}

After the pre-processing of the Landsat 8 Oli image (corrections, band stacking, pan-sharpening, mask extraction, PCA) and of the Digital Terrain Module (mosaic, area extraction, shading), the 5X5 directional filters can then be applied to the different nanochannel's in order to generate lineaments map and their analyses.

The methods used to extract lineaments are convolution methods. This is the Sobel filter used to detect the contours of objects in an image, by making two scans, one horizontal and the other vertical. It often gives good results for the detection of lineaments and directional filters that improve the perception of lineaments, corresponding to lithological or structural discontinuities, by causing an optical effect of cast shadow on the image.

The following figures (Fig.5, Fig.6) show the results of the extraction of the lineaments (in red) from the shadows of the digital terrain model (DTM) on the one hand and the CP1 image on the other hand.

In figure 7 , we presented some statistical processing of the measured fracture directions on the synthetic maps from the filters detail $5 \times 5$ that showed a major NE-SW direction. 


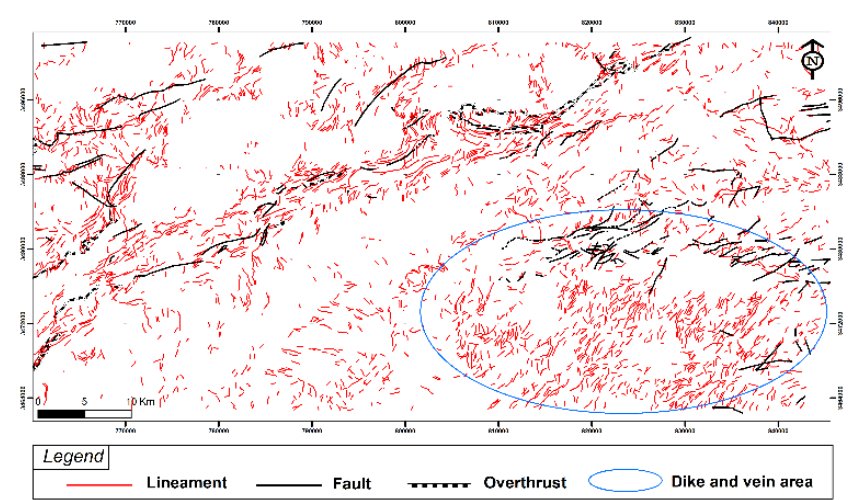

Fig. 5. Map of the lineaments extracted using CP1 band.

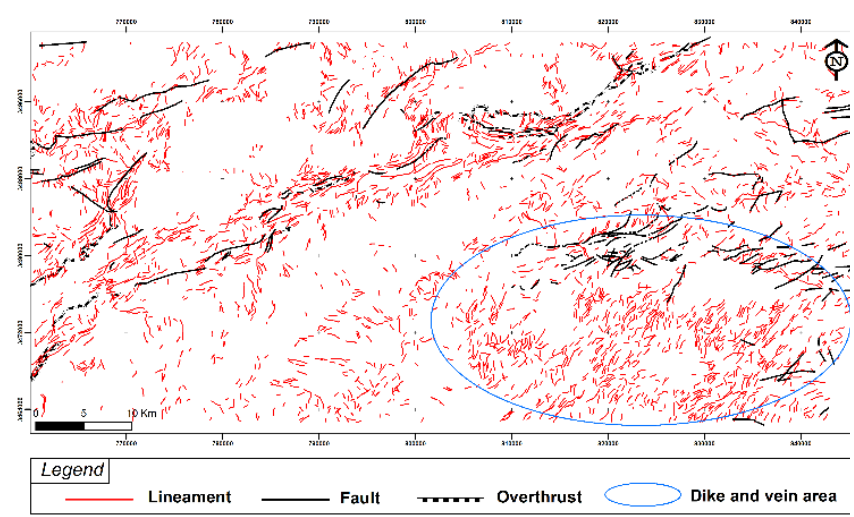

Fig. 6. Map of lineaments extracted using DEM.

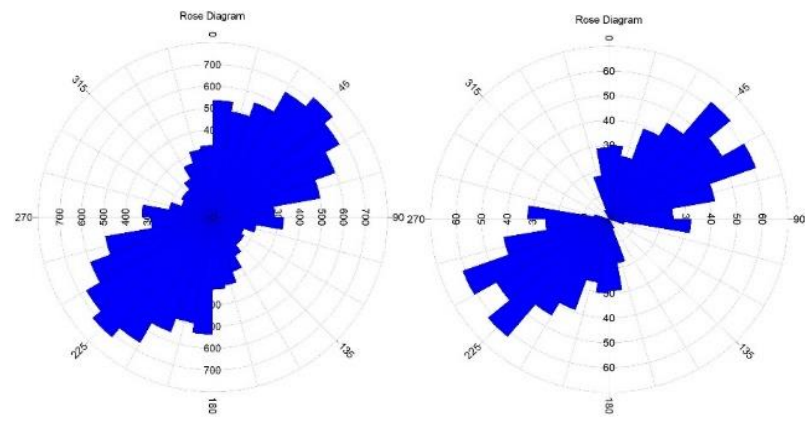

Fig. 7. Lineament roses extracted from PCR1 and DTM successively from right to left.

\subsection{Lithological mapping}

\subsubsection{ACP}

One of the techniques for creating new channels is Principal Component Analysis (PCA) [7].

This technique is widely used in remote sensing, at different spectral domains to condense the information distributed in the many spectral bands of our Landsat 8 OLI scene. The new components of this technique typically represent up to $97 \%$ of the original or initial data set. [8].

After the calculation of the PCA neochannels, it turns out that the color composition (CP3, CP6, CP1) RGB (Fig.13) generated from seven Landsat OLI bands is the best for lithological interpretation.

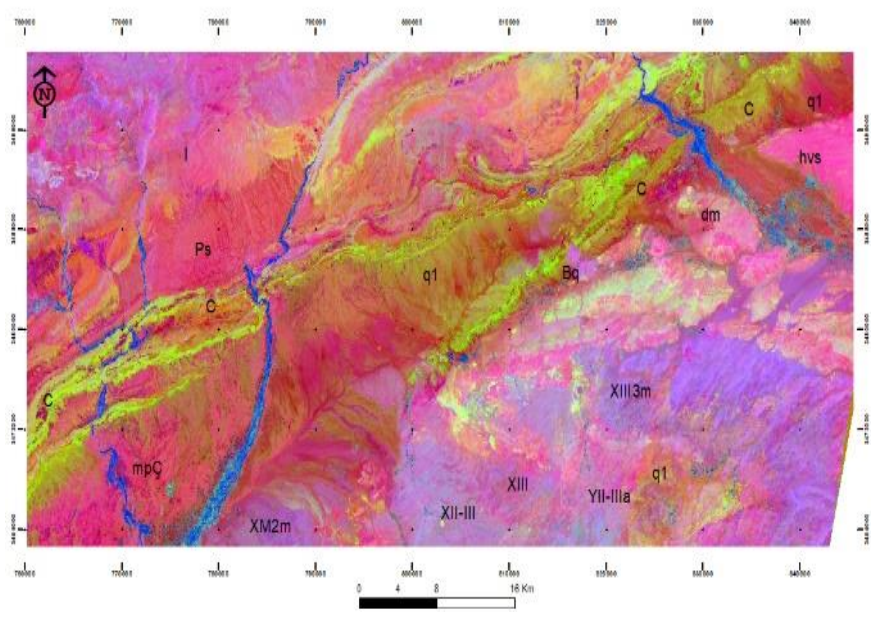

Fig.8. Color composite of the Landsat OLI image, using CP3, CP6, CP1, in RGB. [ L, Ps: C:, mpc :, q1 :, Bq :, dm :, hvs :, XM2m :, XII'III :, XIII :, XIII3m :, YII-IIa]

For the legend of this map see (Jbel Saghrou Dades 1 /200 000), as the majority of the ages are clearly visible. In particular, the two Cretaceous alignments are well distinguished by PCA application (Board. A, and E in the appendix section) (Fig.8).

\subsubsection{SAM}

The SAM method is a supervised classification approach developed by [9]. It considers all spectral bands of the image in an "N-dimensional" spectral space and requires radiometrically and atmospherically calibrated and standardized image data [11]. It is based on a physical concept, which measures the angular similarity between the spectrum of each pixel of the image and the reference spectra, called prototype spectra (Fig.9) or "endmembers". The latter can be measured directly in the field using a spectroradiometer, just as they can be extracted from the image $[\mathbf{1 2}],[\mathbf{1 3}, \mathbf{1 4}, 15]$.

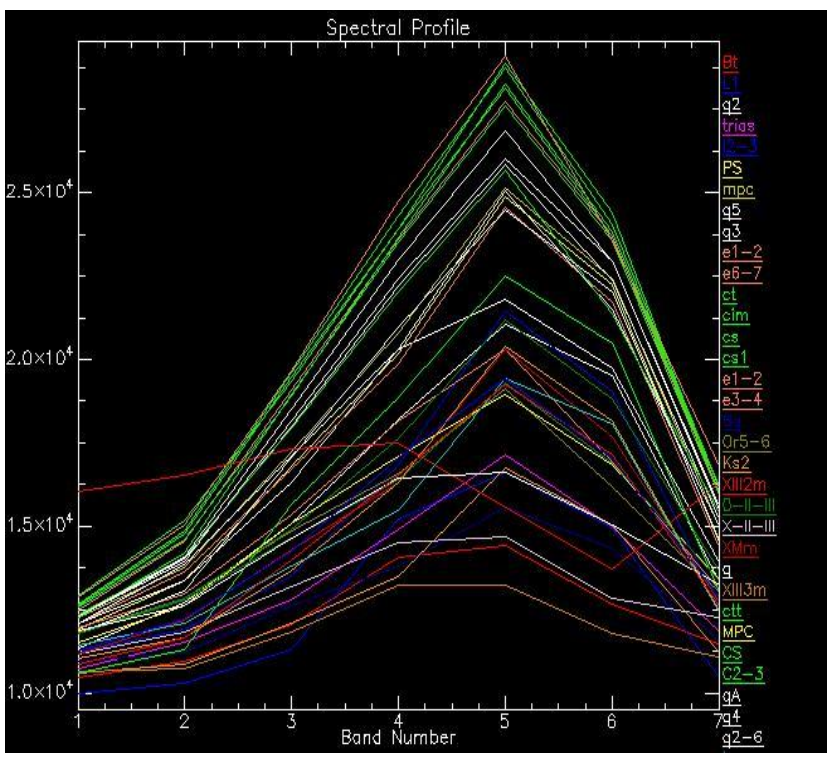

Fig.9. Prototype spectral signatures 


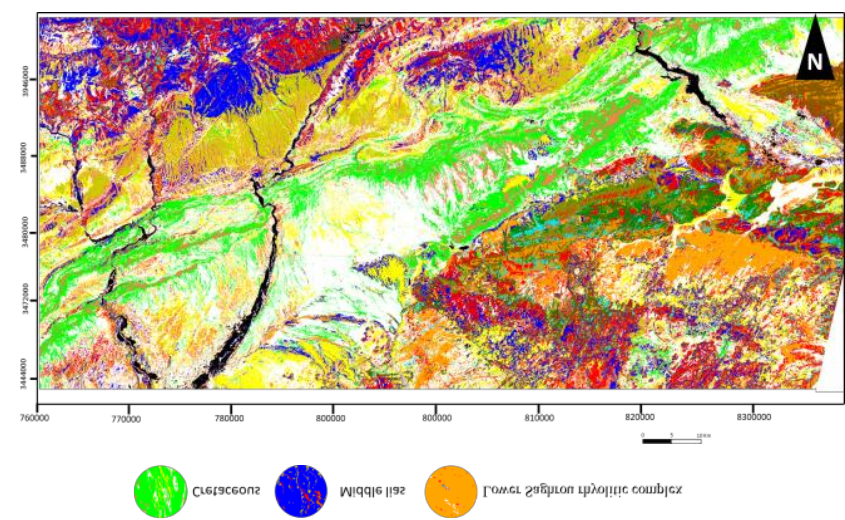

Fig.10. Lithological map of the study area obtained using the $\mathrm{SAM}$ in 2D.

\subsubsection{Maximum Likelihood (ML)}

Supervised Classification using Region of Interests (ROIs) (Fig.10). Regions of interest (ROIs) are portions of images, either selected graphically or selected by other means such as thresholding. These regions can be irregularly shaped and are used to extract statistics for classification. Regions of interests were selected carefully for every rock unit from different localities and were distributed well all over the scene. Selecting these regions were depending upon the field observation and the old maps. Two algorithms were used successfully to classify the images with this (ROIs).

Maximum Likelihood (ML): This classification assumes that the statistics for each class in each band were normally distributed and calculates the probability that a given pixel belongs to a specific class. Unless a probability threshold, all pixels were classified. Each pixel was assigned to the class that has the highest probability (that is, the maximum likelihood).

ENVI implements maximum likelihood classification by calculating the following discriminate functions for each pixel in the image [16]:

$$
g_{i}(x)=\ln p\left(\omega_{i}\right)-1 / 2 \ln \left|\sum_{i}\right|-1 / 2\left(x-m_{i}\right)^{t} \sum_{i}^{-1}\left(x-m_{i}\right)
$$

Where: $\mathrm{i}=$ class; $\mathrm{x}=\mathrm{n}$-dimensional data (where $\mathrm{n}$ is the number of bands); $\mathrm{p}(\omega \mathrm{i})=$ probability that class $\omega \mathrm{i}$ occurs in the image and is assumed the same for all classes; $|\mathrm{i}|$ $=$ determinant of the covariance matrix of the data in class $\omega \mathrm{i} ; \Sigma \mathrm{i}-1=$ its inverse matrix; $\mathrm{mi}=$ mean vector

In the present study, maximum likelihoods were applied on the Landsat OLI bands in the study area using (ROIs) [17] with overall accuracy $90.6 \%$ (Fig. 11).

\subsubsection{Band ratios}

The calculation of the band ratios has made it possible to create new color compositions. The main goal of band ratios is to enhance spectral dissimilarities between lithological unites. Three band ratios $(7 / 6,6 / 5,4 / 2),(7 / 2$, $4 / 2,6 / 7)$ and $(6 / 4,6 / 2,7 / 6)$ were applied successfully in the current study.
The results show that these band ratios are much effective in the discrimination of different rock units of the study area (Fig. 11). Thus, these results found to be correlated to the geological map and to confirm the previously shown results in the above section.

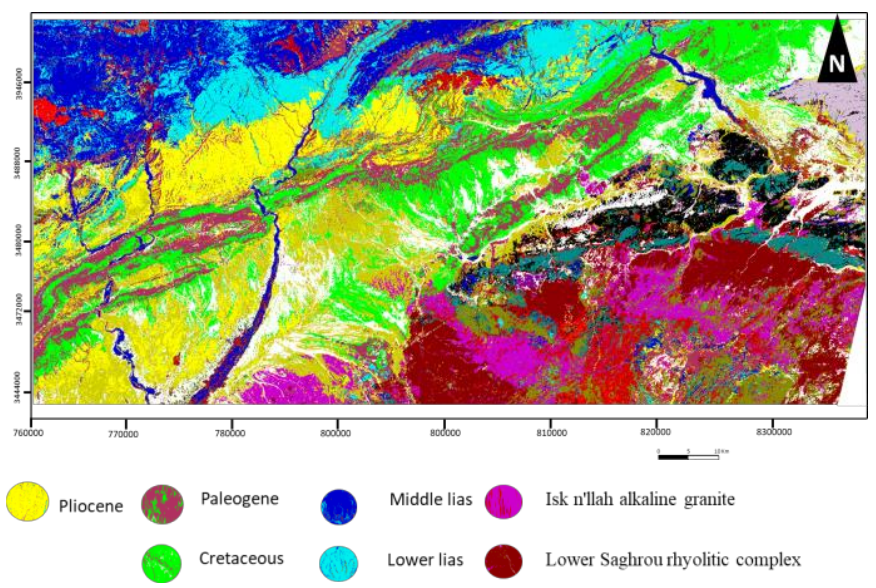

Fig.11. Lithological map of the study area obtained using the 'SL' classification.

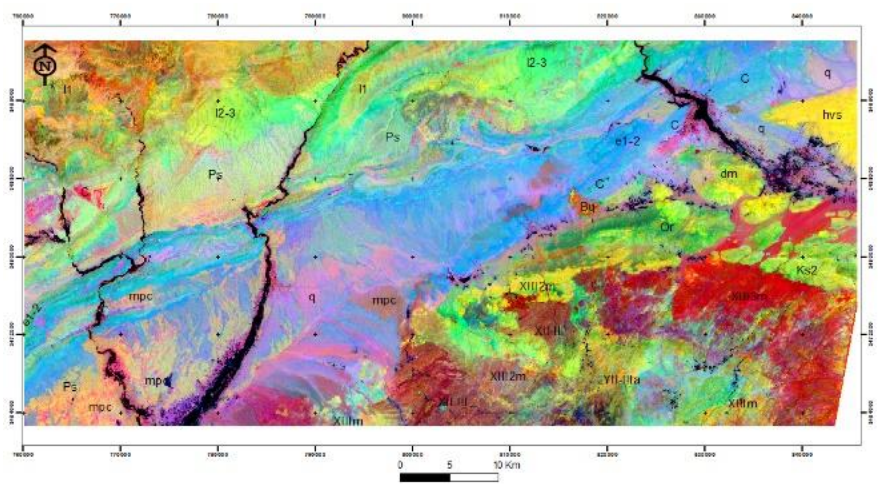

Fig.11. RGB colored compound of the divisions (ratio) of bands: [(7/6); (6/5); (4/2)].

For the legend of this map see (Jbel Saghrou Dade's 1 /200 $000)$, as the majority of the ages are clearly visible (Board. B, C F, G, H and I in the appendix section)

\section{Conclusion}

The work presented in this study focuses on geological mapping, i.e. the extraction of lineaments and lithology in the Central High Atlas of Morocco.

Processing and analysis of the Landsat8 OLI image and DEM type STRM allowed the mapping of linear structures by type in the study area.

The results show that the lineaments extracted from the $\mathrm{CP} 1$ image are very reliable and close to reality after their overlay on the anomalous contact layer of the source geological map in a GIS, and that those extracted from the DEM are not all correct, most correspond to slopes, cliffs and geological layer boundaries.

The analysis of the directional rosettes shows that the lineaments extracted are mainly oriented NE-SW.

From a lithological point of view, processing techniques such as Principal Component Analysis (PCA), supervised 
classification and Band Reports and Indices are important in lithological mapping.

The results of Principal Component Analysis (PCA) were very effective in discriminating the maximum amount of geological information contained in the satellite image as shown in the figure and whose coloured RGB compound in figure. 8 and 11 was selected as the best combination applied to the CP images due to the good discrimination of the lithology.

The results of combining the band ratios on the seven bands of the OLI image to give a result identical to that of the principal component analysis, except that the band divisions were very useful for basement formation lithology discrimination in the north eastern eastern part of the map, essentially.

Another satellite image processing technique has been applied for this mapping, which is the supervised SAM and ML type classification.

Comparing the two classifications (Fig.10, Fig.11), it appears that the ML method to survey all the formations in the geological map (some geological formations are clearly clear as we have determined in the legend), even though the coefficient of validity of both classifications is $99 \%$.

In the light of the results obtained and by reference to field reality, we note that the two approaches considered highlight their potential for lithological mapping, except that the SAM method, despite its potential, requires a good choice of reference prototype spectral signatures, which makes the procedure relatively long and complex.

It is certain that the spectral richness of the OLI sensor has allowed the implementation of these techniques for geological mapping. However, it is desirable to analyse the power of hyperspectral remote sensing in this field of application because this new technology consists of the simultaneous acquisition of images in many narrow and contiguous spectral bands.

\section{Acknowledgments}

We would like to thank the Faculty of Sciences Semlalia Marrakech (FSSM), and also the Centre d'Analyse et de Caractérisation (CAC) for the support that allowed us to overcome some technical problems encountered during the map processing and interpretation as well. Thanks are due to the editor and the anonymous reviewers.

\section{References}

1. Mattauer M, Tapponier P, Proust F (1977) Sur les mécanismes de formation des chaines intracontinentales L'exemple des chaines atlasiques du Maroc. Bull. Soc. geol. France 19 : 521-526.

2. Dewey JF, Helman MNL, Turco E, Hutton DHW, Knott SD (1989) Kinematics of the western Meditettanean. In: Coward M, editor. Alpine Tectonics. Geological Society London Special Publication 45. pp. 265-283.

3. Gomez F, Allmendinger R, Barazangi M, Beauchamp W (2000) Role of the Atlas Mountains (northwest Africa) within the African-Eurasian plate-boundary zone. Geology 28: 769- 8640

4. MICHARD, André, et al. Éléments de géologie marocaine. 1976.

5. MATTAUER, Maurice, TAPPONNIER, Paul, et PROUST, Francois. Sur les mecanismes de formation des chaines intracontinentales ; l'exemple des chaines atlasiques du Maroc. Bulletin de la Société géologique de France, 1977, vol. 7, no 3, p. 521-526.

6. STRAUB, Jeremy. Attitudes towards autonomous data collection and analysis in the planetary science community. Galaxies, 2013, vol. 1, no 1, p. 44-64.

7. ANTOINE, D. Travaux Pratiques de télédétection spatiale. Arlon Campus Environnement, Université de Liège, Belgique, 84p, 2013.

8. DESLANDES, S. Initiation aux méthodes de traitement numérique des images satellites, sur le système PCI Inc. EASUPACE. CARTEL. 32p, 1989.

9. KRUSE, Fred A., LEFKOFF, A. B., BOARDMAN, J. W., et al. The spectral image processing system (SIPS)-interactive visualization and analysis of imaging spectrometer data. In: AIP Conference Proceedings. American Institute of Physics, 1993. p. 192-201.

10. MAIMOUNI, Soufiane, BANNARI, Abderrazak, EL-HARTI, Abderrazak, et al. Indices spectraux et" spectral angle mapper" pour la cartographie des risques d'érosion hydrique à partir des données ali eo1. 2012.

11. BOARDMAN, J. W. et KRUSE, F. A. Automated spectral analysis: a geological example using AVIRIS data, north Grapevine Mountains, Nevada: in Proceedings, ERIM Tenth Thematic Conference on Geologic Remote Sensing. Environmental Research Institute of Michigan, Ann Arbor, MI, pp. I-407-418, 1994.

12. Plaza, A. and Chang, C. (2005) Fast implementation of pixel purity index algorithm. Algorithms and Technologies for Multispectral, Hyperspectral, and Ultraspectral Imagery XI, 28 March 2005, Orlando, FL, USA, vol. 5806, p. 307-317.

13. Kruse, F.A., Lefkoff, A.B., Boardman, J.W., Heidebrecht, K.B., Shapiro, P.J. and Goetz, A.F.H. (1993) The Spectral Image Processing System (SIPS)-Interactive Visualization and Analysis of Imaging Spectrometer Data. Remote Sensing of Environment, vol. 44,p. 145-163.

14. Visualization and Analysis of Imaging Spectrometer Data. Remote Sensing of Environment, vol. 44, p. 145-163.

15. RICHARDS, John A. et RICHARDS, J. A. Remote sensing digital image analysis. Berlin et al.: Springer, 1999.

16. Nangendo, G., Skidmore, A. and Vanoosten, H. (2007) Mapping East African tropical forests and woodlands - A comparison of classifier. SPRS Journal of Photogrammetry and Remote Sensing, vol. $61, n^{\circ} .6$, p. 393-404.

17. MASSIRONI, M., MORATTI, G., ALGOUTI, A., et al. Notice explicative-Carte Géologique du Maroc au 1/50000-Feuille Boumalne. 2007. 


\section{Appendix}

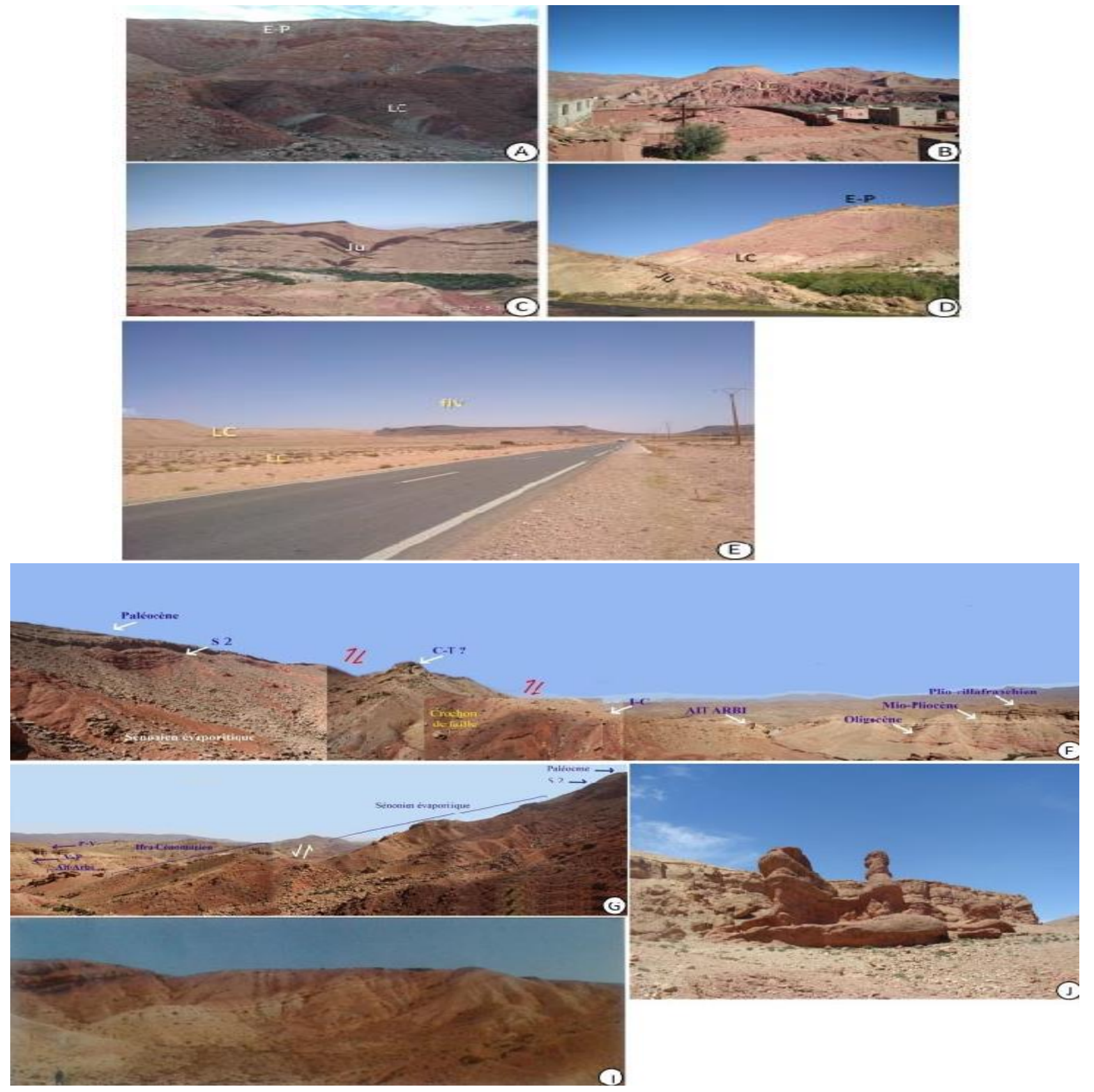

A A. Photo of a panoramic view taken in the region of BOUMALNE showing the two geological formations, the Upper Cretaceous, which is capped by EocenePaleocene formation.

$\circ$ B. Photo of a panoramic view taken in the region of BOUMALNE showing the senonian evaporitic series.

$\circ$ C. Photo of a panoramic view taken in the region of KELAAT MGOUNA TIMSTIGHIT showing the fabulous forms of Jurassic formation.

$\circ \mathrm{D} \& \mathrm{H}$. Photo of a panoramic view taken in the region of KELAAT MGOUNA TIMSTIGHIT showing the succession of the three geological formations, from Jurassic to Upper Cretaceous the all of them is capped by Paleocene Eocene.

$\circ$ E. Photo of a panoramic view taken in the region of IMIDER-TINGHIR showing upper and lower cretaceous formation, right next to the foum LKOUS VOLCANO.

$\circ \mathrm{F} \& \mathrm{G}$. Photo of a panoramic view taken in the region of AIT IBREREN -BOUMALNE showing succession of the geological formations of vilafranchian miopliocene oligocene infracenomanien cenomanoturien, then the Upper cretaceous and finally the carbonate Paleocene.

O I. Photo of a panoramic view taken in the region of AIT IBREREN -BOUMALNE showing Paleo-valley deposits of Villafranchian age according to the instruction note on the map of BOUMALNE [14].

$\circ \mathrm{J}$. Photo of a panoramic view taken in the region of AIT IBREREN -BOUMALNE showing Ait-Arbi Eocene Formation. 